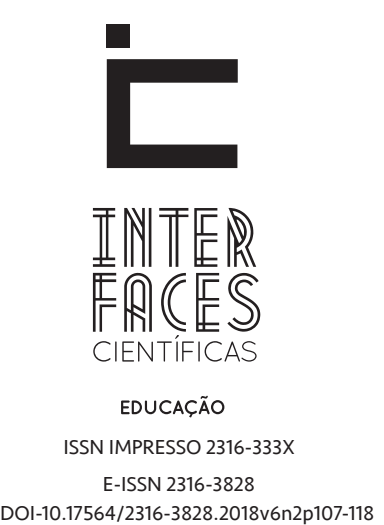

\title{
ENSINO DE ARTE E FORMAÇ̃̃O DOCENTE: METODOLOGIAS E GRADE CURRICULAR DE CURSOS DE PEDAGOGIA NO PARANÁ
}

ARTS TEACHING AND PROFESSORS PREPARATION: METHODOLOGIES AND THE CURRICULUM OF PEDAGOGY COURSES IN PARANÁ.

ENSEÑANZA DE ARTE Y FORMACIÓN DOCENTE: METODOLOGÍAS Y MALLA CURRICULAR DE CURSOS DE PEDAGOGÍA EN PARANÁ

Diego Geovan dos Reis ${ }^{1}$

Poliana Fabíula Cardozo ${ }^{2}$

Viviane Cristina Princival ${ }^{3}$

\section{RESUMO}

0 presente estudo versa acerca da formação docente para o ensino de arte. De um modo específico, desenvolve-se aqui uma reflexão a partir de pesquisa on- line na grade curricular de cursos de graduação em Pedagogia de dez universidades paranaenses com o intuito de localizar o ensino de arte nas metodologias de ensino na formação do professor pedagogo, que comumente atua com o ensino de arte nos anos iniciais da educação básica. Realiza-se igualmente nesta pesquisa, uma revisão bibliográfica ao que concerne ao ensino de arte, bem como ao amparo legislativo para a arte na educação básica, por meio da Lei de Diretrizes e Bases da Educação Nacional (LDBEN) e suas respectivas alterações em relação a este conteúdo. Embora garantido por lei, o ensino de arte ainda perpassa outros desafios como o da própria formação docente, uma vez que há escassez em professores egressos do curso de Arte nas séries iniciais da educação básica e é o professor pedagogo que atua no desenvolvimento desta disciplina. Visando entender qual vem a ser o tratamento dado pelos cursos de graduação em Pedagogia no estado do Paraná para o ensino de Arte nas metodologias de ensino de suas grades curriculares, firma-se, portanto, a presente reflexão.

\section{PALAVRAS-CHAVE}

Formação de Professores. Ensino de Arte. Metodologia de Ensino. 


\section{ABSTRACT}

The present study states about professors education for the teaching of Arts. In a specific way, it is developed a reflection from online research in the curriculum of undergraduate courses in Pedagogy from ten universities in the State of Paraná, Brazil, aiming to locate the teach of Arts in the methodologies of teaching in the professors learning processes, who commonly work with Arts education in the early years of basic education. This paper also carries out a bibliographical revision regarding the teaching of Arts, as well as to the legislative support for Arts in basic education, through the Guidelines and Statements for National Basic Educational Law - LDBEN, and its respective changes in relation to this content. Althou$\mathrm{gh}$ it is guaranteed by law, Arts education still faces others challenges, such as professors preparation, since there is a shortage of professors with a degree of Arts courses in the initial series of basic education and it is the pedagogue who acts in the development of this discipline. Aiming to understand what the treatment given by undergraduate courses in Pedagogy in the State of Paraná are for the teaching of Arts in the teaching mythologies of its curricular grades, the present reflection is therefor stated.

\section{KEYWORDS}

Teachers preparation. Arts teaching. Teaching Methodology.

\section{RESUMEN}

El presente estudio versa sobre la formación docente para la enseñanza de arte. De un modo específico, se desarrolla aquí una reflexión a partir de la investigación online en la parrilla curricular de cursos de grado en Pedagogía de diez universidades paranaenses con el objetivo de localizar la enseñanza de arte en las metodologías de enseñanza en la formación del profesor pedagogo que, comúnmente, actúa con la enseñanza de arte en los años iniciales de la educación básica. Se realiza también en esta investigación, una revisión bibliográfica a lo que concierne a la enseñanza de arte, así como al amparo legislativo para el arte en la educación básica, por medio de la Ley de Directrices y Bases de la Educación Nacional - LDBEN, y sus respectivas alteraciones en relación a este contenido. La enseñanza de arte, todavía, atravesó otros desafíos como el de la propia formación docente, ya que hay escasez en profesores egresados del curso de Arte en las series iniciales de la educación básica y es el profesor pedagogo que actúa en el desarrollo de esta disciplina. Con el fin de entender cuál viene a ser el tratamiento dado por los cursos de grado en Pedagogía en el estado de Paraná para la enseñanza de Arte en las metodologías de enseñanza de sus mallas curriculares, se firma, por lo tanto, la presente reflexión.

\section{PALABRAS CLAVE}

Formación de profesores. Enseñanza de Arte. Metodología de enseñanza 


\section{INTRODUÇÃ̃O}

Pensar o ensino de Arte na educação básica após as alterações pelas quais passou a Lei de Diretrizes e Bases (LDB) da Educação Nacional remete também a pensar sobre a formação docente propriamente dita. Considerando a escassez de professores egressos da licenciatura em Arte para atuar na educação básica, é o professor pedagogo que comumente assume o desenvolvimento desta disciplina nas séries iniciais. Todavia, faz-se necessário atentar para a forma como os cursos da graduação em Pedagogia concebem o ensino de arte em si.

Deste modo, neste trabalho, busca-se compreender como as matrizes curriculares de universidades paranaenses inserem em seu currículo a questão do ensino de arte dentro das metodologias de ensino. Esta investigação se dá aqui, por meio de uma pesquisa on-line junto de sites de dez instituições paranaenses de ensino superior, que apresentam o curso de Pedagogia, verificando a matriz do currículo de seus respectivos cursos. Do mesmo modo um amparo legislativo norteará por assim dizer, o entendimento do ensino de Arte no âmbito da educação nacional, o que vem ao encontro da problematização deste estudo: a questão da formação docente.

As alterações que concernem à disciplina de Arte na Lei de Diretrizes e Bases da Educação Nacional especificam a obrigatoriedade do ensino de arte em suas linguagens específicas e gera amiúde, o prazo de adaptação da efetivação do mesmo. A discussão da ausência de profissionais da área de Arte com licenciatura para atuar na educação básica abre um rol de distintas discussões quanto às práticas pedagógicas, o que estas de fato realizam e o que acabam deixando de lado. Nisto, o professor pedagogo contempla tais práticas cotidianas no entorno escolar para o ensino de arte, mesmo que o curso de Pedagogia apresente naturalmente em seu currículo, a Arte apenas dentro das metodologias de ensino. Buscar-se-á aqui, identificar como os cursos de graduação em Pedagogia atentam para o ensino de Arte em suas grades curriculares.
Desta reflexão, espera-se atingir a compreensão de muitos elementos da realidade atual do ensino de Arte na educação básica, tendo em foco a formação docente, sobretudo ao que tange à formação inicial do professor pedagogo.

\section{A LDBEN E AS DIRETRIZES CURRICULARES NACIONAIS E O ENSINO DE ARTE}

A Lei de Diretrizes e Bases da Educação Nacional constou de várias discussões acerca do ensino de Arte. Incluído no currículo escolar pela LDB de 1971, o ensino de arte vem como Educação Artística, mas não como uma disciplina propriamente dita e sim como uma atividade educacional. Em 1988, diante de discussões na área da Educação, a educação artística beirou o risco de ser extinta do cotidiano pedagógico. E somente com a LDB promulgada no ano de 1996 é que a Arte foi reconhecida enquanto uma disciplina para a educação básica. Assim diz o parágrafo $2^{\circ}$ do artigo 26: "O ensino da arte constituirá componente curricular obrigatório, nos diversos níveis da educação básica, de forma a promover o desenvolvimento cultural dos alunos".

A partir do ano de 2008, a lei 11.769 que altera a LDB 9394/96 garante a obrigatoriedade do ensino de Artes Plásticas, Artes Cênicas, Dança e Música dentro das aulas de Arte. Já a lei 13.278/2016 inclui as Artes Visuais, a Dança, a Música e o Teatro na matriz curricular dos diferentes níveis da educação básica. Esta lei também vem alterar a Lei de Diretrizes e Bases da Educação Nacional 9394/96 e estabelece, portanto, um prazo de cinco anos para a adaptação dos sistemas de ensino em promover a formação docente em prol da implantação desses componentes na grade curricular da educação básica, desde a educação infantil ao ensino médio.

Uma nota importante nesta alteração legislativa decorrente do ano de 2016 prevê implicações regio- 
nais para o ensino de Arte. A questão de regionalismos para o ensino de Arte abrange um aporte cultural. Entende-se dentro das teorias de currículo, de acordo com Silva (1999), que o tema cultura é concebido a partir das teorias curriculares pós-críticas. Forquin (1993), por sua vez, apresenta uma discussão a partir do que a escola deve de fato ensinar, uma vez que os limites da relação cultura e ensino se fazem móveis em um contexto complexo e ambíguo que é a pós-modernidade e sua atual compreensão de identidade de cultura. Todavia, a inserção de elementos regionalistas para o ensino de Arte, faz-se então garantida pela alteração da LDB decorrente do ano de 2016.

Estas ultimas mudanças sobre o ensino de arte na Lei de Diretrizes e Bases da Educação Nacional, asseguram o exercício pleno das quatro linguagens artísticas em si como conteúdos disciplinares. A alteração do nome Artes Plásticas para Artes Visuais, a obrigatoriedade do ensino de música e a implementação de aspectos regionalistas garantem, de acordo com as discussões legislativas, o pleno desenvolvimento cultural dos alunos.

Ao considerar que a educação estética possibilita aos sujeitos consideráveis benefícios e isso reflete diretamente em benefícios para a vida em sociedade, faz-se importante apropriar-se da afirmação de Duarte Junior (2001) a respeito dos saberes estéticos e aos conhecimentos artísticos, tão necessários a uma sociedade regressivamente estigmatizada pela racionalidade puramente instrumental. Vem a ser por meio dos processos criativos e dos conhecimentos adquiridos nas aulas de Arte, uma possibilidade de reverter os indícios desta racionalidade técnica.

Ainda a respeito do amparo legislativo para o ensino de Arte na educação básica, faz-se relevante mencionar as Diretrizes Curriculares Nacionais para a Educação Infantil (BRASIL, 2010, p. 16) e a Arte constando em seus princípios norteadores:

As propostas pedagógicas de Educação Infantil devem respeitar os seguintes princípios: Éticos: da autonomia, da responsabilidade, da solidariedade e do respeito ao bem comum, ao meio ambiente e às diferentes culturas, identidades e singularidades. Políticos: dos direitos de cidadania, do exercício da criticidade e do respeito à ordem democrática. Estéticos: da sensibilidade, da criatividade, da ludicidade e da liberdade de expressão nas diferentes manifestações artísticas e culturais.

Encontrar a garantia da educação estética num dos princípios que orientam o trabalho pedagógico nas Diretrizes Curriculares Nacionais para a Educação Infantil reafirma a necessidade de um comprometimento docente para com o ensino de arte deste a sua formação inicial. As propostas em Arte estão asseguradamente inseridas na Educação Infantil.

Uma vez contextualizada a discussão e o amparo legislativo para com o ensino de Arte, faz-se relevante atentar para a formação do professor que irá atuar de fato, esta disciplina na educação básica. Embora estes novos elementos estejam assegurados por lei para o ensino das artes nos diferentes níveis da educação básica, é importante compreender que nas séries iniciais, nem sempre é um professor licenciado em Artes que irá atuar. Há uma considerável escassez de professores egressos de cursos de Arte para atuar nos primeiros anos da educação básica e nesta ausência, quem acaba assumindo o ensino de arte é então o professor pedagogo.

Direcionemos a presente reflexão, portanto, aos egressos da graduação em Pedagogia, e o que estes professores contemplam em sua formação inicial na graduação quanto ao ensino de arte.

\section{REFLEXÕES À FORMAÇÃO DO PROFESSOR PEDAGOGO QUE TRABALHA COM OENSINO DEARTE}

Ao considerar a necessidade de professores que atuem no ensino de Arte nas séries iniciais da educação básica, uma vez que há menos professores licenciados em Artes do que em relação a professores pedagogos, estes acabam por assumir a Arte no entorno pedagógico. A formação inicial do professor 
pedagogo, por sua vez, deve contemplar o ensino das artes e o presente escrito objetiva fomentar uma reflexão em torno da Arte no currículo da graduação em Pedagogia.

O enlace reflexivo ocasionado por Nóvoa (1992) sugere pensar tanto a formação da profissão docente, quanto a formação de professores em relação ao seu desenvolvimento pessoal, ambos diante do desenvolvimento organizacional da escola.

De acordo com Teixeira (2015, p. 12):

A Lei de Diretrizes e Bases da Educação Nacional (LDBEN 9.394/96), assevera que é finalidade da educação superior estimular a criação cultural e o desenvolvimento do espírito científico e do pensamento reflexivo, formar diplomados nas diferentes áreas do conhecimento, incentivar o trabalho de pesquisa e investigação científica, promover a divulgação dos conhecimentos culturais e científicos e colaborar com o aperfeiçoamento profissional contínuo.

Dentre os aspectos da formação em Pedagogia, vem a calhar, na presente reflexão, assumindo, portanto o caráter de desenvolvimento deste espírito científico e de um pensamento reflexivo, os seguintes aspectos: a função da Arte no currículo do curso, se uma ferramenta pedagógica para o ensino de conteúdos de outras disciplinas, ou a Arte pela arte em si, em seus saberes artísticos e conhecimentos estéticos. A questão dos planos de ensino dos professores que atuam com o ensino de arte nos cursos de pedagogia, como eles concebem a arte, como se apropriam da arte e até a formação destes professores. E a questão do espaço que o ensino de Arte ocupa na matriz curricular do curso de Pedagogia. Exceto esta última questão que será abordada, separadamente, no item seguinte do artigo, sequencialmente.

Ao que diz respeito à função da Arte no currículo do curso de Pedagogia, de acordo com a compreensão da Lei de Diretrizes e Bases da Educação Nacional e suas respectivas alterações para o ensino de arte na educação básica, o currículo de uma graduação que vise à formação docente também para o ensino de Arte deveria contemplá-la em suas teorias, enquanto uma disciplina específica, possibilitando sua práxis por meio de processos criativos nas aulas de arte. Todavia isso nem sempre se dá.

Em muitas vezes, é comum diagnosticar a presença da Arte na formação do pedagogo limitada e erroneamente posta apenas enquanto ferramenta de ensino para outros conteúdos, oriundos de qualquer outra disciplina, como por exemplo, uma música para o ensino de matemática e não dos elementos da música em si, ou a confecção de um cartaz e ou painel para a fixação de conteúdos de ciências, e não uma instalação artística, com poética, materialidades e técnicas artísticas de elaboração propriamente ditas. Ou ainda, alguma encenação ou coreografia para datas comemorativas e não para explorar a relação entre corpo e movimento, interpretação, dramaturgia e direção de espetáculo de dança ou de teatro.

Há inúmeras e atraentes possibilidades para o ensino de arte na educação básica, pois são inúmeras as suas necessidades, uma vez que os alunos deste primeiro nível da educação básica, que é a educação infantil e as séries iniciais, sentem-se favorecidos com as práticas artísticas, ou seja, os processos criativos, pois estes ao se desenvolverem por conteúdos da arte, abordam aspectos de socialização e outras instâncias da vida em comunidade, como o momento certo de cantar, atuar, ou de harmonizar uma composição visual, ou por assim dizer, de interagir na elaboração de um processo criativo e coletivo em Arte.

Outro aspecto relevante vem a ser a elaboração dos planos de ensino dos professores que atuam com o ensino de Arte na graduação em Pedagogia. Uma vez que é aí que se estabelece o fio condutor das práticas pedagógicas para o seu ensino. Isto se relaciona, sobremaneira, à formação deste professor; com a forma com que este se apropria da Arte e a concebe perante o amparo legislativo e as necessidades do entorno escolar. É comum que nem sempre seja um professor da área das artes a atuar com a sua disciplina de Teoria e Metodologia de ensino, e isso reflete diretamente na formação dos graduandos em pedagogia.

Outro exemplo comum é a rotatividade de professores nos departamentos, o que gera outra tensão na formação do pedagogo: a ausência de um professor 
efetivo e estável para o ensino de Arte faz com que se rompa certa linearidade para o cumprimento da ementa da disciplina, e os graduandos podem, ocasionalmente, sair prejudicados com a ausência de determinados conteúdos, que, em um primeiro momento podem não apontar grande importância, mas que, na prática pedagógica cotidiana poderiam fazer uma grande diferença.

É fundamentalmente necessário atentar para a Arte numa perspectiva que embora possa sustentar links de trabalho interdisciplinar, é um conteúdo independente. A Arte se sustenta como disciplina em seus conteúdos e é amparada por lei em seu pleno desenvolvimento. Quando Duarte Junior (2001) fala da educação do sensível, compreende-se nas aulas de Arte este processo de sensibilização por meio dos saberes estéticos apreendidos na realização das atividades artístico-pedagógicas.

Rosa (1988) ao discorrer sobre a educação musical para a formação dos sujeitos, afirma que as sociedades que tiveram seus membros formados musicalmente desde tenra idade alcançaram inúmeros benefícios nas mais diversas áreas, citando a ciência, a literatura e o cinema, mas que isso se reflete como um todo na formação integral dos sujeitos e consequentemente no desenvolvimento pleno da sociedade a que estão inseridos.

Contudo, ao pensar especificamente a educação musical, o musicólogo ambientalista e educador musical Murray Schafer (1991; 2009) ao sugerir uma tríade compreensão do ensino de música alicerçada no ouvir, pensar e criar, sugere ao professor que o primeiro passo prático é, justamente, dar o primeiro passo e isso implica diretamente na sua formação. Um professor comprometido inicialmente com a sua própria formação e atualização terá as condições de desenvolver tais práticas artísticas, sobretudo para este autor, ao que diz respeito às possibilidades de uma educação musical.

Há ainda a questão do espaço que o ensino de Arte literalmente ocupa na matriz do currículo da graduação em Pedagogia, ou seja, quais disciplinas relacionadas à Arte, a Pedagogia contempla na sua car- ga horária e qual sua disposição nas séries do curso. Geralmente em uma abordagem didática, as disciplinas relacionadas ao ensino de Arte estão na segunda metade da graduação em Pedagogia, podendo variar. Mas, para além das disciplinas específicas, há presença da arte de forma complementar, no desenvolvimento de outras disciplinas, sobretudo as que dizem respeito à educação infantil.

Com o intuito de conferir a realidade de cursos de Pedagogia no Paraná e sua atenção para o ensino de arte, o próximo tópico apresenta uma pesquisa realizada junto dos websites de dez instituições de ensino superior do estado do Paraná.

\section{ENSINO DE ARTE E A GRADE CURRICULAR DE CURSOS DE PEDAGOGIA DE UNIVERSIDADES DO PARANÁ}

Por meio de uma pesquisa realizada on-line, junto aos sites de dez instituições paranaenses de ensino superior, foi possível diagnosticar os seguintes dados a respeito da matriz curricular dos cursos de Pedagogia: na Faculdade Guairacá, instituição privada, localizada no município de Guarapuava, consta na grade curricular do curso de Pedagogia, as seguintes informações sobre o ensino de arte: na matriz curricular do ano de 2008 há a disciplina de Fundamentos e metodologia da Arte, constante no $4^{\circ}$ período do curso, numa carga horária semestral de 90 horas aula. Essa informação se mantém na matriz curricular firmada no ano de 2010 e na matriz firmada no ano de 2012.

A Universidade Positivo (UP), instituição privada, localizada em Curitiba, consta em sua grade curricular sobre a arte: na $2^{\mathrm{a}}$ série da licenciatura a disciplina de Arte e cultura, com carga horária de 80 horas aula, e na $4^{\mathrm{a}}$ série da licenciatura há a disciplina de Conteúdos e Metodologias do Ensino de Arte com carga horária de 80 horas aula. Estas duas disciplinas são anuais.

A Pontifícia Universidade Católica do Paraná (PUCPR), instituição privada, localizada em Curitiba, 
consta da Arte em sua grade curricular: na Matriz dos ingressantes no ano de 2012 há no $5^{\circ}$ período do curso, a disciplina de Metodologia do Ensino da Arte I e Metodologia do Ensino da Arte II, no $6^{\circ}$ período, ambas com carga horária de 60 horas aula. Na matriz dos ingressantes do ano de 2013, 2014, e a partir de 2015 há a disciplina de Metodologias do ensino de Arte na Educação Infantil e Anos Iniciais no $3^{\circ}$ período do curso.

A Faculdade do Centro do Paraná (UCP), instituição privada, localizada em Pitanga, consta da Arte em seu currículo: a disciplina de Metodologia do ensino da Arte e da música, no $6^{\circ}$ período do curso, com a carga horária semestral de 80 horas aula.

A Universidade Estadual de Londrina (UEL), não consta da arte em sua matriz curricular do curso de Pedagogia.

A Universidade Estadual de Maringá (UEM), consta da arte na primeira série do curso de Pedagogia, com a disciplina de Formação Docente: Prática de Ensino de Arte na Escola, com carga horária de 68 horas aula. Na $3^{a}$ série há a disciplina de Educação, Mídia e Arte, também com carga horária de 68 horas aula, enquanto uma disciplina complementar semipresencial.

A Universidade Estadual de Ponta Grossa (UEPG), por sua vez, consta da Arte: a disciplina de Ludicidade, corporeidade e Arte, com carga horária de 68 horas aula, sem especificar no site, a série do curso em que se insere.

A Universidade Federal do Paraná (UFPR), localizada em Curitiba, apresenta Arte no currículo da Pedagogia pela disciplina de Metodologia do Ensino de Artes, no $2^{\circ}$ ano, com carga horária semestral. E para, além disso, há, também, a disciplina optativa de Arte na Escola.

A Universidade Estadual do Centro Oeste (UNICENTRO), consta da Arte na $3^{a}$ série do curso de Pedagogia, com a disciplina de Teoria e Metodologia do Ensino da Arte, numa carga horária de 68 horas aula.

A Faculdades Integradas do Vale do Ivaí (UNIVALE), instituição privada, localizada no município de Ivaiporã, consta da arte no currículo da sua graduação em Pedagogia com a disciplina de Metodologia do Ensino de Arte no $5^{\circ}$ semestre do curso, com uma carga horária de 85 horas aula.

\subsection{DISCUSSÃO E ANÁLISE}

Por meio da investigação on-line realizada junto da matriz curricular do curso de Pedagogia destas dez instituições paranaenses de ensino superior, é possível compreender que embora em uma carga horária restrita, em sua maioria há a presença da Arte na formação do professor pedagogo. Se comparada com as outras metodologias de ensino, a carga horária desta disciplina se equivale, mas considerando as quatro linguagens artísticas, as possibilidades pedagógicas que apresentam, sobretudo, as necessidades na sala de aula das séries iniciais, é provável que essa carga horária seja insuficiente. É preciso atentar que a Arte serve em um duplo viés na educação básica: ao ensino e aprendizado da Arte em si como conteúdo e também uma ferramenta pedagógica para o ensino de outras disciplinas.

Aí vem a calhar o entendimento desta diferença e, muitas vezes, a Arte na formação do pedagogo entra como um auxílio para a transmissão de outros conteúdos, mas não contempla os conhecimentos estéticos e nem os saberes artísticos das aulas de Arte. Muitas vezes o professor que assume as disciplinas relacionadas ao ensino das artes na graduação em Pedagogia, nem ele é egresso da formação em Arte propriamente dita, ou se apropriou da arte neste viés de ferramenta de ensino, não concebendo os elementos teóricos e metodológicos do desenvolvimento de práticas de processo criativo nas distintas linguagens artísticas para o cotidiano pedagógico do ensino artístico.

Das dez universidades observadas, apenas uma delas não apresentou visivelmente a Arte dentre as disciplinas do curso. Todavia, em uma perspectiva otimista, pode-se esperar talvez a arte conforme mencionada anteriormente: nas metodologias de ensino de outras disciplinas, mas sem um conhecimento dos saberes artísticos em si. Há, nesta referida instituição em que se ausenta a Arte do currículo, disciplinas 
como a de "saberes e fazeres na educação infantil", e, de acordo com as expectativas pedagógicas para esse período letivo, acreditar-se-á que elementos da Arte vêm ao encontro de tais necessidades pedagógicas para o desenvolvimento de alunos nesta fase letiva.

Em outra instituição ainda, há o elemento "plano de estudos interdisciplinares" como constituinte de disciplinas da matriz curricular. Também abre aqui um leque para possibilidades com a arte, porém ainda na transmissão de conteúdos específicos de outras disciplinas, ou quem sabe a realização de projetos. A ausência do esclarecimento da presença de elementos específicos da arte é que provoca o questionamento se há realmente ensino de Arte ou não, além de possíveis expectativas.

Não há também conhecimento dos temas dos trabalhos e ou textos de conclusão de curso dos alunos destas dez instituições de ensino superior. Em outra pesquisa direcionada a isto, seria possível diagnosticar os temas e conhecer se há a arte na intenção de suas pesquisas e consequentemente a arte como um interesse de suas práticas docentes, prospecto este para uma possível pesquisa posterior, podendo dar continuidade a este trabalho.

Na maioria destas instituições, a ementa das disciplinas não está disponível no endereço eletrônico. Muito embora, apesar de ser possível acessar algumas das ementas destas disciplinas relacionadas ao ensino de Arte, não é possível acessar o plano de ensino de seus professores, nem verificar o encaminhamento pedagógicao destas disciplinas e por assim dizer não há como saber se tais professores apropriam-se erroneamente da arte apenas como ferramenta pedagógica para o ensino de conteúdos de outras disciplinas, ou se abordam de fato elementos estéticos, conhecimentos artísticos da arte pela arte enquanto conteúdo específico.

A existência de outras disciplinas mencionadas nas matrizes curriculares verificadas, relacionadas à educação infantil, possivelmente trazem em seu bojo a presença da arte. Barbieri (2012) discorre sobre o local da arte na infância e apresenta o caráter sinestésico desta fase de desenvolvimento infantil atrelada aos conteúdos da Arte. Como deveria se pensar então o ensino de arte neste nível educacional? Ostetto (2008) ao falar sobre os saberes e fazeres na formação de professores para a educação infantil, mencionados os benefícios de registros didáticos para as práticas cotidianas, com o intuito de mapear uma linearidade no desenvolvimento dos alunos em seu processo de aprendizado.

Pensar a elaboração de portfólios para o ensino de Arte pode ser uma boa sugestão no viés do ensino dos conteúdos das linguagens artísticas se de organização das propostas. 0 aluno será acompanhado no desenvolvimento do seu aprendizado artístico, será possível traçar uma avaliação tanto do estudante quanto das metodologias de ensino utilizadas pelo professor.

Entende-se que não unicamente na educação infantil, mas igualmente nas séries iniciais onde está o professor pedagogo, que há possibilidades relacionadas a questões inclusive de corpo e movimento nas quais certamente há resquícios de dança, dramaturgia e consciência corporal. Godard (2000, p. 11) apresenta na relação corpo e movimento, a questão do gesto e da percepção corporal. Essas potencialidades da relação corpo e movimento podem ser exploradas na educação infantil e nas séries iniciais por meio das aulas de Arte, no favorecimento de propostas pedagógicas do ensino de dança, da consciência corporal e da relação da cultura na consciência do corpo, bem como em aspectos de socialização dos alunos, do entendimento do seu lugar no grupo, na qualidade da comunidade escolar enquanto membro ativo e consciente de sua carga identitária de cultura.

Katz e Greiner (2001) por sua vez, exploram as questões de corpo e movimento para a dança pela abordagem do corpo enquanto mídia, ou enquanto um modelo de comunicação entre natureza e cultura. Se conduzirmos a afirmação destas autoras para o ensino de dança e outras vivências de corpo e movimento na educação básica, é possível traçar um paralelo entre muitos elementos culturais dos alunos, como as vivências familiares, religiosas, de lazer e outras condições da vida em comunidade. Por meio de propostas em dança é possível apreender, pela leitura corporal 
dos alunos, muito de suas vivências e ajudá-los na compreensão de uma consciência cultural por meio do corpo. As aulas de dança não se fazem só vitrine, exposição disso, mas propiciam além do aprendizado da dança em si, outros elementos que vêm a contribuir com essa educação estética visada nas aulas de Arte.

Notas sobre musicalização, igualmente, ganham importância no entendimento de práticas pedagógicas de iniciação e socialização na educação infantil. Cunha e Gomes (2012, p. 18), ao discorrer sobre o fazer musical na escola afirmam que:

\begin{abstract}
A música é uma das manifestações culturais da sociedade, e faz parte do cotidiano escolar. Desse modo, cabe à escola dar oportunidade a todos de se manifestar sob as mais variadas formas, oferecendo, com a prática da música, um meio de expressão tão necessário como o falar, o escrever ou o desenhar. Com a obrigatoriedade da sua presença na escola como conteúdo, a prática da educação musical precisa ser pensada e analisada diante da problemática cultural na qual se insere.
\end{abstract}

Por isso é necessário atentar para como se dão as propostas de uma educação musical na educação básica, com o cuidado de que além da expressão musical, haja de fato o processo de ensino e de aprendizado de elementos musicais, haja compreensão de nuances musicais e não o ensino de conteúdos de outras disciplinas nessa investida musical. Outras vertentes das artes visuais também possivelmente aparecem no desenvolvimento de muitas disciplinas mencionadas nestas matrizes de currículo do curso de Pedagogia. Resta compreender de que forma, se em amparo meramente ilustrativo ou se há de fato entendimento de suas teorias. As disciplinas relacionadas às metodologias de ensino para a graduação em Pedagogia perpassam uma abordagem didática. É a didática, assim, o elemento responsável para que ocorra efetivamente o aprendizado. A didática é a ponte entre o objeto a ser estudado e o aprendizado em si.

Deste modo é relevante refletir que as práticas pedagógicas que inicialmente se dão na graduação em Pedagogia são igualmente sustentadas por correntes de pensamento de seus professores e a formação dos pedagogos percorre um discurso ideológico. E embora seja possível diagnosticar a presença da arte na matriz curricular da Pedagogia, a única forma de compreender o desenvolvimento das ementas das disciplinas postas pelos planos de ensino de seus professores, vem a ser acompanhar o cotidiano letivo de suas aulas e a efetivação de suas práticas de ensino. Isso irá repercutir como um eco nas práticas pedagógicas de seus alunos, neste caso os futuros professores pedagogos, que embora ainda não tendo concluído sua graduação, já atuam como estagiários nas redes de ensino de diferentes níveis da educação básica.

\section{CONSIDERAÇÕES FINAIS}

O ensino de Arte na educação básica, embora seja assegurado por lei, enfrenta determinadas tensões ao que diz respeito à formação docente. Não é suficiente o número de professores licenciados em Arte e isso implica na inserção de professores pedagogos para as aulas de Arte na educação infantil e nas séries iniciais da educação básica. Seria necessária uma nova investigação, em uma escala maior, acerca destes professores pedagogos e seus respectivos planos de aula para o ensino de Arte, para identificar a realidade escolar de tais práticas. Neste estudo, de um modo específico, buscou-se mapear a presença da Arte na formação inicial do pedagogo, que é a graduação.

Ao considerar que a Arte está notoriamente presente na matriz curricular do curso de Pedagogia da maioria das dez instituições paranaenses do ensino superior que foram investigadas nesta pesquisa, é possível compreender que a presença da Arte nestes currículos é limitada. Esta afirmação se justifica no duplo viés da relação entre a Arte e o ensino: a arte enquanto conteúdo e a Arte assumida enquanto uma ferramenta pedagógica ao desenvolvimento de outros conteúdos, de outras disciplinas. A carga horária das disciplinas relacionadas ao ensino de Arte na formação do professor pedagogo é restrita a um semestre, ou a uma carga horária ínfima em um contexto anual.

Logo, entende-se que para o pedagogo atuar com 
o ensino de Arte, ele precisa buscar possibilidades de formação continuada para melhor se capacitar. Cursos extensionistas e ou de especialização em Arte vêm a contribuir, por assim dizer, para sua formação continuada, atentando-se sempre pela escolha de cursos que tenham uma relação intrínseca com a didática e metodologia artística, com o real ensino de Arte. Muitas vezes o professor até pode vivenciar a formação paralela em alguma linguagem artística, como as artes visuais ou até a formação instrumental em algum conservatório de música. Todavia, o ensino de Arte para a educação básica visa uma iniciação aos conhecimentos artísticos pelas aulas de Arte e não necessariamente a formação de artistas. A Arte na educação básica perpassa nuances de uma educação estética e o pleno desenvolvimento deste saber sensível e dos conhecimentos em Arte é uma questão de docência.

\section{REFERÊNCIAS}

BARBIERI, S. Interações: onde está a arte na infância. São Paulo: Blucher, 2012.

BRASIL. Ministério da Educação. Secretaria de Educação Básica. Diretrizes Curriculares Nacionais para a Educação Infantil. Brasília: MEC/SEB, 2010.

BRASIL. Lei de Diretrizes e Bases da Educação Nacional - LDBEN. Disponível em: <http://www. planalto.gov.br/ccivil_03/leis/L9394.htm> Acesso em: jul 2017.

\section{CUNHA, D.S.S. GOMES. E.D. Música na escola?}

Reflexões e possibilidades. Guarapuava: Unicentro, 2012.

DUARTE JUNIOR, F. 0 sentido dos sentidos: a educação do sensível. Curitiba, 2001.

FACULDADE GUAIRACÁ. Pedagogia. Disponível em: <http://guairaca.com.br/graduacao/pedagogia/> Acesso em: Jul 2017.
FACULDADES INTEGRADAS DO VALE DO IVAÍ UNIVALE. Pedagogia. Disponível em: < http://www. univale.com.br/unisite/\#> Acesso em: Jul 2017.

FORQUIN, J.C. Escola e cultura: as bases sociais e epistemológicas do conhecimendo escolar. Tradução de Guacira Lopes Louro. Porto Alegre: Artes Médicas, 1993.

GODARD, H. Gesto e percepção. In: ANTUNES; A. et al. Lições de Dança 2. Rio de Janeiro: UniverCidade, 2000.

KATZ, H.; GREINER, C. Corpo e Processos de Comunicação. Revista Fronteiras: estudos midiáticos, v.III, n.2, dezembro de 2001. Disponível em: <http://www.helenakatz.pro.br/midia/ helenakatz71314110790.pdf>. Acesso em: 5 ago. 2016.

NÓVOA, A. Formação de professores e profissão docente. In: NÓVOA, A. (Coord.). Os professores e a sua formação. Lisboa: Dom Quixote, 1992.

OSTETTO, L. Educação infantil: saberes e fazeres da formação de professores. Campinas: Papirus, 2008.

PONTIFÍCIA UNIVERSIDADE CATÓLICA DO PARANÁ. Pedagogia. Disponível em: <http://www.pucpr.br/ graduacao/pedagogia/> Acesso em: Jul. 2017.

REDE ARTE NA ESCOLA. Disponível em: <http:// artenaescola.org.br/>. Acesso em: Jul. 2017.

ROSA, L. Musicalização para a educação infantil. São Paulo: Irmãos Vitale, 1988.

SCHAFER, R.M. 0 ouvido pensante. São Paulo: UNESP, 1991.

SCHAFER, R.M. Educação sonora: 100 exercícios de escuta e criação de sons. Tradução de Marisa Trench de Oliveira Fonterrada. São Paulo: Melhoramentos, 2009. 
SILVA, T.T. Documentos de identidade: uma introdução às teorias de currículo. Belo Horizonte: Autêntica, 1999.

TEIXEIRA, M.C. Metodologia do ensino superior. Guarapuava: Unicentro, 2015.

UCP - Faculdades do Centro do Paraná. Pedagogia. Disponível em: <http://ucpparana.edu.br/>. Acesso em: Jul 2017.

UNIVERSIDADE ESTADUAL DE LONDRINA.

Pedagogia. Disponível em: <http://www.uel.br/ceca/ pedagogia/>. Acesso em: Jul 2017.

UNIVERSIDADE ESTADUAL DE MARINGÁ. Pedagogia. Disponivel em: <http://sites.uem.br/pen/deg/apoioaos-colegiados-aco/documentos/cursos-1/cursos/ pedagogia-matutino-noturno>. Acesso em: Jul 2017.

UNIVERSIDADE ESTADUAL DE PONTA GROSSA.

Pedagogia: Disponível em: <http://uepg.vwi.com.br/ conteudo/37/Pedagogia>. Acesso em: Jul 2017.

UNIVERSIDADE ESTADUAL DO CENTRO OESTE.

Pedagogia. Disponível em: <http://www3.unicentro. br/>. Acesso em: Jul 2017.

UNIVERSIDADE POSITIVO. Pedagogia. Disponível em: <http://www.up.edu.br/graduacao/pedagogiapresencial>. Acesso em: Jul. 2017.

UNIVERSIDADE FEDERAL dO PARANÁ. Pedagogia. Disponível em: <http://www.pedagogia.ufpr.br/>. Acesso em: Jul 2017. 
1 Graduado em Turismo pela Universidade Estadual do Centro-Oeste - UNICENTRO. Especialista em Metodologia do Ensino Superior pelo Centro Universitário Internacional - UNINTER. Mestre em Educação pela Universidade Estadual do Centro-Oeste - UNICENTRO. Email: diego.gdosreis@ gmail.com.

Professora adjunto do curso de Bacharelado em Turismo da Universidade Estadual do Centro-Oeste - UNICENTRO. Graduada em Turismo pela UNIOESTE. Mestre em Turismo pela Universidade de Caxias do Sul - UCS. Doutora em Geografia pela Universidade Federal do Paraná - UFPR. Email polianacardozo@yahoo.com.br.

2 Graduada em Pedagogia pela Universidade Estadual do Centro-Oeste UNICENTRO. Graduada em Arte Educação pela UNICENTRO. Mestre em Educação pela UNICENTRO. Email: vivi_princivall@hotmail.com 